\title{
Ultrastructural and Immunochemical Changes During the In Vitro Development of Plasmopara halstedii
}

\author{
Sandrine Bouterige, Guy Tronchin, Maurice Lesourd, Agnès Marot-Leblond, Valérie Molinéro, \\ Jean-Philippe Bouchara, and Raymond Robert
}

First, second, fourth, sixth, and seventh authors: Groupe d'Etude des Interactions Hôte-Parasite, UPRES-EA 3142, Laboratoire de Parasitologie-Mycologie, Faculté de Pharmacie, 16 Bd. Daviers, 49100 Angers; third author: Service Commun de Microscopie Electronique, Faculté de Médecine, rue Haute de Reculée, 49045 Angers, France; and fifth author: Groupe d'Etude des Variétés et des Semences, rue Georges Morel, 49071 Beaucouzé Cedex, France. Accepted for publication 18 March 2003.

\section{ABSTRACT}

Bouterige, S., Tronchin, G., Lesourd, M., Marot-Leblond, A., Molinéro, V., Bouchara, J.-P., and Robert, R. 2003. Ultrastructural and immunochemical changes during the in vitro development of Plasmopara halstedii. Phytopathology 93:1023-1030.

The asexual phase of the life cycle of Plasmopara halstedii, the causal agent of downy mildew of sunflower, plays a key role in the propagation of the disease. We investigated the morphological and ultrastructural changes that occur during the asexual development of the pathogen. Direct examination of infected cotyledons confirmed the presence of sporangiophores. In contact with water, important ultrastructural changes occurred, affecting the surface of zoosporangia, which became smoother, and their cytoplasm, which differentiated into flagellate zoospores. The subsequent encystment of zoospores was characterized by the synthesis of a cell wall and the loss of the flagella. In addition, two monoclonal antibodies (MAbs) specific for $P$. halstedii were used to analyze the immunochemical changes associated with these modifications. MAb 16A6, which bound to a 48-kDa glycoprotein, mainly labeled the surface of mobile or encysted zoospores and of mother cells of germ tubes. Conversely, MAb 2F9, which recognized highly glycosylated antigens, labeled the surface of zoosporangia and of flagellate zoospores, but not the encysted zoospores. These results provide new insights into the morphological and ultrastructural changes associated with the release and the encystment of zoospores which may be interesting targets for the development of new antimicrobial products.
Plasmopara halstedii (Farlow) Berlese et de Toni, which belongs to the class Oomycetes and to the order Peronosporales, is one of the most economically important pathogens of sunflower crops (Helianthus annuus L.) $(7,15,18,21)$. This obligate parasite causes dramatic damage in almost all areas where sunflower is cultivated. Infection of the plant usually results from the attack of roots and cotyledons by zoospores released in the soil by zoosporangia arising from the germination of oospores. Zoosporangia produced on the leaf surface may also be disseminated by wind and, in a humid environment, they may release zoospores responsible for systemic infection of neighboring plants. Indeed, secondary infection, mainly aerial, results in numerous changes in the metabolism and in the development of the plant, including the loss of the phototropic response, leaf chlorosis, and degeneration of the underground tissues (2), as well as a higher respiration rate and alterations in carbohydrate and secondary metabolisms $(4,20)$. However, the most obvious symptom of systemic infection is the typical growth reduction of the plants $(15,21)$.

Secondary spread, therefore, is considered an important process in the disease cycle. However, little is known about the asexual phase of $P$. halstedii and most of the information on its life cycle is based on data obtained on other phytopathogenic Peronosporales. The present work, therefore, was conducted to provide morphological and ultrastructural data about the in vitro developmental stages of $P$. halstedii. In addition, two monoclonal antibodies (MAbs) that specifically recognize different antigens of this pathogen were used to analyze the immunochemical changes that occur

Corresponding author: R. Robert; E-mail address: raymond.robert@univ-angers.fr

Publication no. P-2003-0616-01R

(C) 2003 The American Phytopathological Society during the maturation of zoosporangia, as well as during the encystment and the germination of released zoospores.

\section{MATERIALS AND METHODS}

Culture conditions of $\boldsymbol{P}$. halstedii. $P$. halstedii race 100 was used throughout this study. This isolate was maintained by GEVES (Groupe d'Etude des Variétés et des Semences, Angers, France) on sunflower line HA89 ('Peredovick'). Artificial infections were carried out by immersing whole seedlings according to the procedure of Cohen and Sackston (6) modified by Champion (5).

Zoosporangia and hyphae were collected by scraping 10 infected cotyledons with a paintbrush in $1 \%$ saccharose solution. The suspension was then adjusted to $5 \times 10^{6}$ cells per $\mathrm{ml}$ and incubated at 16 to $18^{\circ} \mathrm{C}$ with gentle shaking for $4 \mathrm{~h}$. Under these conditions, the first zoospores were released in the culture medium after $2 \mathrm{~h}$ of incubation, and encysted zoospores initiated germ tube formation $1 \mathrm{~h}$ later. Zoospores were separated from zoosporangia as described by Oros and Viranyi (17) and pelleted at $180 \times g$ for $10 \mathrm{~min}$.

Hybridoma production and characterization. Hybridoma were obtained by fusion of X63/Ag 8.653 myeloma cells with spleen cells of Balb/c mice immunized against a somatic extract of zoosporangia and hyphae as previously described (3). Among the different hybridoma obtained, two were selected for studies of the immunochemical changes that occur during the maturation of zoosporangia and the germination of zoospores.

Isotypes of these MAbs designated 16A6 and 2F9 were determined by enzyme-linked immunosorbent assay (ELISA) with anti-isotype antibodies (Caltag Laboratories, Burlingame, CA).

The molecular mass of the antigens recognized by these MAbs was evaluated by sodium dodecyl sulfate-polyacrylamide gel 
electrophoresis (SDS-PAGE) and western blotting. To this aim, antigens from zoosporangia and hyphae were extracted by sonication in distilled water (three times $5 \mathrm{~min}, 24 \mathrm{~W}$ ). Cell debris was then discarded by centrifugation at $12,000 \times g$ for $10 \mathrm{~min}$. Samples of the resulting supernatant were electrophoresed on 5 to $15 \%$ gradient polyacrylamide slab gels according to Laemmli (14). After electrophoresis, proteins were stained with Coomassie brilliant blue or transferred electrophoretically to $0.45-\mu \mathrm{m}$ pore size Immobilon membranes (Millipore Corp., Bedford, MA) as described by Towbin et al. (22). Blots were saturated overnight at $4^{\circ} \mathrm{C}$ in $10 \%$ nonfat dry milk in $0.15 \mathrm{M}$ phosphate buffered saline (PBS; pH 7.2), washed in PBS, and incubated for $1 \mathrm{~h}$ with undiluted culture supernatants. After washing, the mem- branes were incubated for $1 \mathrm{~h}$ with alkaline phosphatase-conjugated goat anti-mouse immunoglobulin G (IgG) $\gamma$ chain antibodies (Caltag Laboratories) diluted 1:300 in PBS. Finally, bands were detected by nitroblue tetrazolium and 5-bromo-4-chloro-3indolyl phosphate substrate system. Molecular mass of the antigens was calculated from the migration of molecular mass standards (Sigma Chemical Co., St. Louis): myosin, $205 \mathrm{kDa}$; $\beta$-galactosidase, $116 \mathrm{kDa}$; phosphorylase $\mathrm{b}, 97.4 \mathrm{kDa}$; bovine serum albumin (BSA), $66 \mathrm{kDa}$; ovalbumin, $45 \mathrm{kDa}$; and carbonic anhydrase, $29 \mathrm{kDa}$.

Antigen sensitivity to proteolytic enzymes and chemical agents was also investigated by western blotting and ELISA as previously described (3). Briefly, the effect of 2-mercaptoethanol
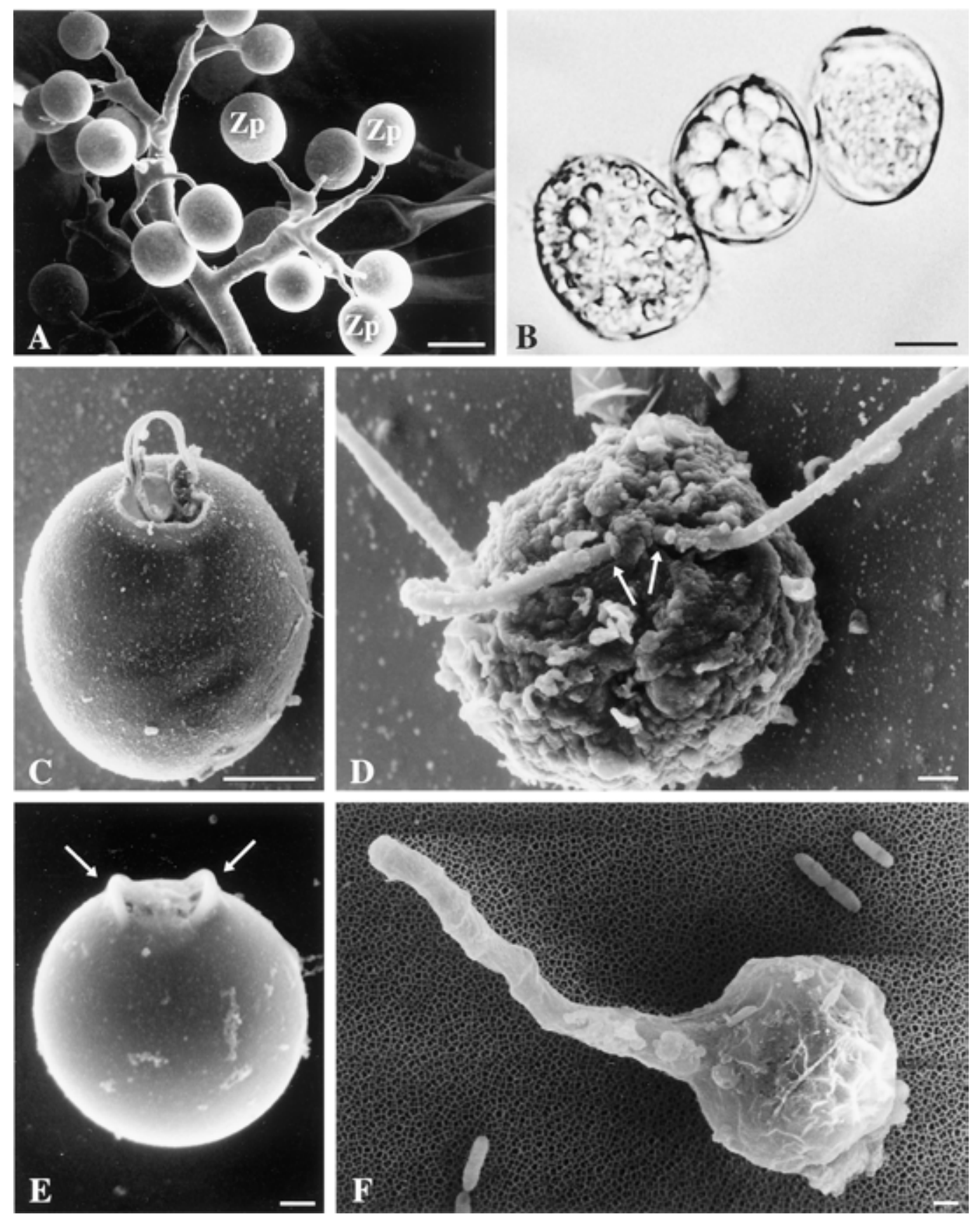

Fig. 1. Morphological changes associated with the maturation of zoosporangia and the germination of zoospores visualized by $\mathbf{A}$ and $\mathbf{C}$ to $\mathbf{F}$, scanning electron microscopy (SEM) and B, phase-contrast microscopy. A, Tree-shaped sporangiophore revealed by SEM directly at the leaf surface of an infected cotyledon. Note the numerous branches in the upper region of the sporangiophores, with secondary branches also diverging at right angles. Two to five sterigmata each bearing a zoosporangium (Zp) are seen on the secondary branches. B, Following incubation in 1\% saccharose, the cytoplasmic granular mass of zoosporangia progressively differentiated into zoospores. C, Flagellate zoospores were released from the zoosporangia through an apical papilla and $\mathbf{D}$, appeared free in the culture medium after $2 \mathrm{~h}$ incubation. D, Note the presence of two smooth flagella arising laterally from the same area (arrows). E, Encysted globose to subglobose zoospore with two rounded warts (arrows). F, Germ tube arising from the mother encysted zoospore. Bars correspond to A and B, $20 \mu \mathrm{m} ; \mathbf{C}, 10 \mu \mathrm{m}$; and $\mathbf{D}$ to F, $1 \mu \mathrm{m}$. 
(2-ME) was determined by the addition of 5\% 2-ME to the pathogen extract prior to electrophoresis. The pathogen extract immobilized on Immobilon sheets or on microtiter plates was incubated for $1 \mathrm{~h}$ with either pronase $\mathrm{E}(2.5 \mathrm{mg} / \mathrm{ml})$ or proteinase $\mathrm{K}$ $(0.16 \mathrm{mg} / \mathrm{ml})$ diluted in PBS, $\mathrm{pH}$ 7.6. After washing and incubation in nonfat dry milk, immunoreactivity with the MAbs was determined as described previously. Periodate oxidation $(20 \mathrm{mM}$, $30 \mathrm{~min}$ ) was performed by incubating the immobilized antigens at room temperature in the dark (25). Results were compared with those obtained in the absence of any treatment.

Indirect immunofluorescence. Zoosporangia and hyphae collected from infected cotyledons, and zoospores and germ tubes obtained by incubation of zoosporangia in $1 \%$ saccharose, were pelleted by centrifugation. The resulting pellets were resuspended in $1 \mathrm{ml}$ of undiluted hybridoma culture supernatants. After incubation for $1 \mathrm{~h}$ at $37^{\circ} \mathrm{C}$ with gentle shaking followed by washing in PBS, the elements of the pathogen were incubated for $1 \mathrm{~h}$ at $37^{\circ} \mathrm{C}$ in $200 \mu \mathrm{l}$ of a 1:100 dilution of fluorescein isothiocyanate-conjugated goat anti-mouse IgG $\gamma$ chain antibodies (Caltag Laboratories). After washing, $20 \mu \mathrm{l}$ of the suspension was placed on glass slides, and the preparations were examined with a Nikon microscope (Nikon France SA, Champigmy-Sur-Marne) equipped with epifluorescence. Specificity of the labeling was assessed by incubation of the different morphological stages in PBS instead of the culture supernatants or by using a nonspecific MAb directed against the yeast Candida albicans (16).

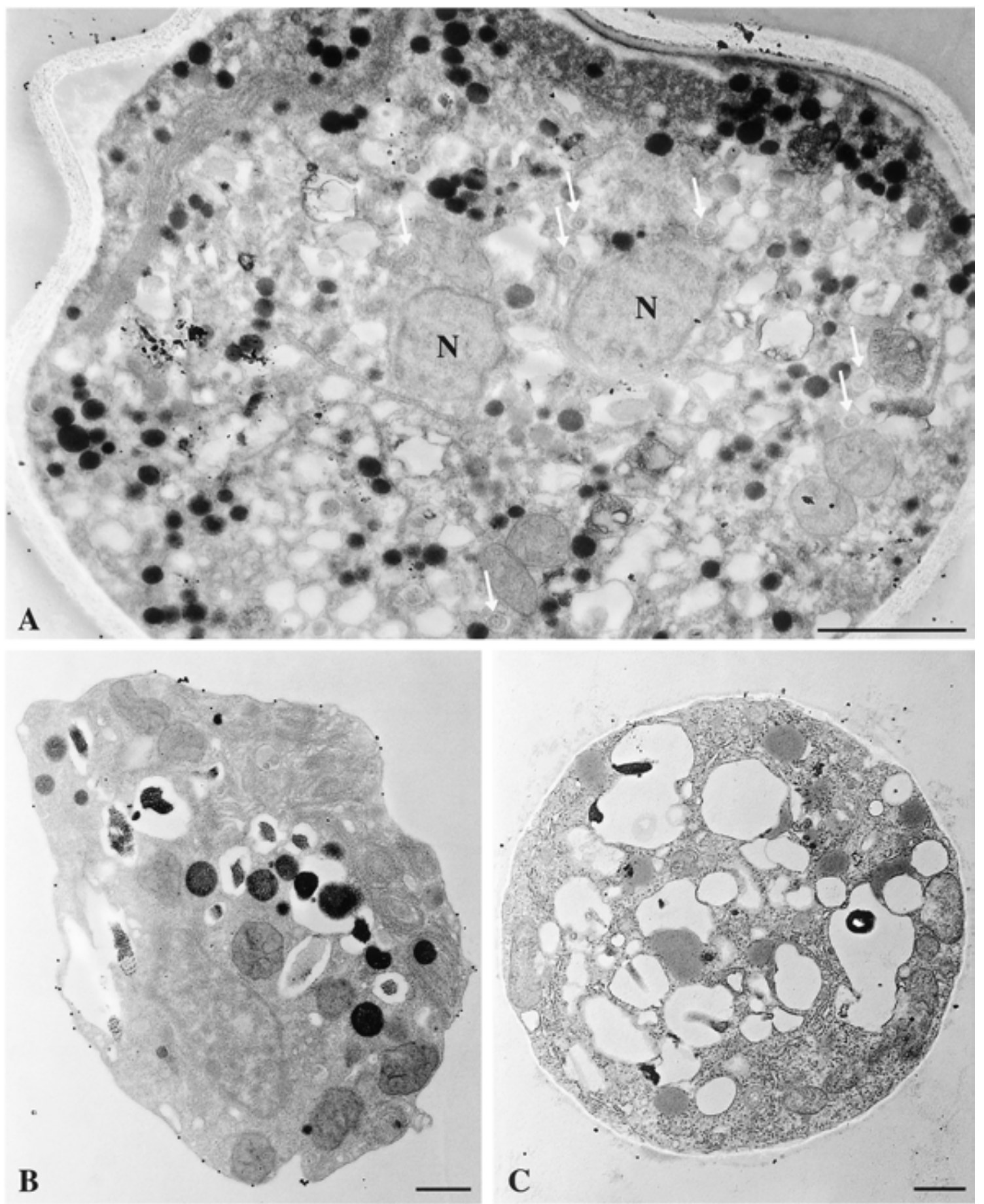

Fig. 2. Ultrastructural changes associated with the maturation of zoosporangia and the germination of zoospores revealed by transmission electron microscopy. A, A zoosporangium initiating its differentiation into zoospores. Note the numerous flagellar sections (arrows) and nuclei (N). B, A flagellate zoospore and $\mathbf{C}$, an encysted zoospore recognizable by its regular shape due to the presence of a cell wall. Bars correspond to $1 \mu \mathrm{m}$. 
Scanning electron microscopy. Infected cotyledons, and the morphological stages obtained by incubation of zoosporangia in $1 \%$ saccharose, were fixed for $1 \mathrm{~h}$ with freshly prepared fixative (0.1\% glutaraldehyde- $2 \%$ paraformaldehyde) buffered at $\mathrm{pH} 7.4$ with $0.1 \mathrm{M}$ sodium cacodylate. Following washes in PBS, samples were postfixed with $2 \%$ glutaraldehyde in cacodylate buffer, washed again, and dehydrated in ethanol. The samples were then treated with hexamethyldisilazan for $10 \mathrm{~min}$ and finally coated with carbon for $3 \mathrm{~min}$. Observations were made on a scanning electron microscope (Model $6301 \mathrm{~S}$; JEOL Europe SA, France).

For immunodetection of the antigens, the elements of $P$. halstedii fixed in glutaraldehyde-paraformaldehyde were washed in cacodylate buffer containing $10 \mathrm{mM} \mathrm{NH}_{4} \mathrm{Cl}$ and incubated for $1 \mathrm{~h}$ at $37^{\circ} \mathrm{C}$ with $1 \mathrm{ml}$ of undiluted hybridoma culture supernatants. After additional washes in PBS- $0.1 \%$ BSA, the pellets were incubated for $1 \mathrm{~h}$ at $37^{\circ} \mathrm{C}$ in $500 \mu \mathrm{l}$ of a $1: 100$ dilution of protein A-gold (20 nm; Sigma Chemical) and subsequently postfixed and treated as aforementioned. The specificity of the immunostaining procedures was established by omission of the culture supernatants or by using an anti-C. albicans MAb.

Ultrastructural immunolocalization of the antigens. Distribution of the antigens was also investigated by transmission electron microscopy (TEM). Pathogen elements were fixed for $30 \mathrm{~min}$ at room temperature with $0.1 \%$ paraformaldehyde buffered at $\mathrm{pH}$ 7.4 with $0.1 \mathrm{M}$ cacodylate and then washed in the same buffer. Thereafter, samples were successively incubated for $1 \mathrm{~h}$ at $37^{\circ} \mathrm{C}$ with $1 \mathrm{ml}$ of undiluted culture supernatants and $1 \mathrm{ml}$ of protein Agold $(20 \mathrm{~nm})$ with three washes in PBS between each step. They were then fixed with $2.5 \%$ glutaraldehyde, postfixed for $1 \mathrm{~h}$ in $1 \%$ $\mathrm{OsO}_{4}$ in cacodylate buffer, dehydrated in ethanol, and embedded in Epon. Thin sections were contrasted with uranyl acetate and examined on a microscope (100 CX; JEOL). As already mentioned for scanning electron microscopy (SEM), controls of the specificity of the labeling consisted in omission of the culture supernatants or in the use of a nonspecific MAb. As for immunofluorescence studies and SEM, experiments were repeated at least

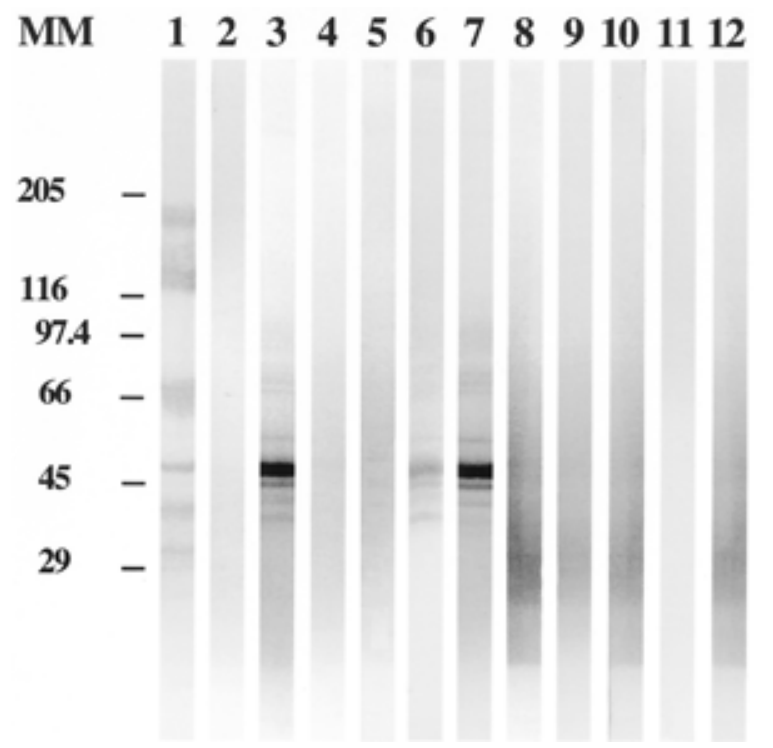

Fig. 3. Characterization of the antigens detected by monoclonal antibodies (MAbs) 16A6 and 2F9. Coomassie blue staining of a sodium dodecyl sulfate-polyacrylamide gel electrophoresis (SDS-PAGE) of Plasmopara halstedii extract (lane $1 ; 80 \mu \mathrm{g}$ of protein per lane). Western blot detection of the antigens recognized by MAb 16A6 (lanes 3 to 7) or 2F9 (lanes 8 to 12) without prior treatment of the crude extract (lanes 3 and 8) or after treatment with pronase $\mathrm{E}$ (lanes 4 and 9), proteinase $\mathrm{K}$ (lanes 5 and 10), or $20 \mathrm{mM}$ periodate (lanes 6 and 11). Controls consisted in omission of the MAbs (lane 2) or incubation of the blots with acetate buffer prior to the addition of the MAb (lanes 7 and 12). Molecular mass (MM) in kilodaltons of the protein standards is indicated on the left. twice, and for each morphological stage, about 20 specimens were observed.

\section{RESULTS}

In vitro development of $\boldsymbol{P}$. halstedii. Direct examination of infected cotyledons by SEM revealed the presence of sporangiophores at the leaf surface. They were arborescent, branching in their upper part at right angles to the main axis (Fig. 1A). Secondary branches, also diverging at right angles, supported two to five tips or sterigmata, each bearing an ellipsoidal to cylindrical zoosporangium.

Zoosporangia collected from infected cotyledons by scraping and incubated in $1 \%$ saccharose were also examined by phasecontrast microscopy and electron microscopy. In contact with water, numerous ultrastructural changes occurred, affecting both the cytoplasm and the surface of zoosporangia. Their granular cytoplasmic mass progressively differentiated into zoospores (Fig. 1B) and, at a more advanced stage, an apical papilla was seen, which permitted the release of the newly formed flagellate zoospores (Fig. 1C). These zoospores, which appeared mobile in the culture supernatant after $2 \mathrm{~h}$ incubation, presented two flagella arising laterally from the same area (Fig. 1D). Thereafter, the flagella disappeared, leading to globose to subglobose encysted zoospores recognizable by their smooth surface with two rounded warts, which could correspond to the insertion points of the flagella (Fig. 1E). Prolonging the incubation time up to $3 \mathrm{~h}$ resulted in the emission of germ tubes by the encysted zoospores (Fig. 1F).

These morphological changes were also investigated by TEM. After incubation at 16 to $18^{\circ} \mathrm{C}$, several nuclei and numerous flagellar sections, characterized by the typical arrangement of microtubules in a ring of nine doublets with one central doublet, were observed in the cytoplasm of zoosporangia, thus attesting to the differentiation into mobile zoospores (Fig. 2A). Likewise, TEM easily distinguished two types of zoospores: the flagellate zoospores with numerous mitochondria, a well developed endoplasmic reticulum and lipid globules, some of these globules being phagocytized in vacuoles (Fig. 2B); and the encysted zoospores with a more regular shape due to the presence of a cell wall (Fig. 2C).

Characterization of MAbs. Among the different hybridoma obtained by fusion of X63/Ag 8.653 myeloma cells with lymphocytes of immunized mice, MAbs $16 \mathrm{~A} 6$ and 2F9, which were found to be $\operatorname{IgG1}$, were selected for further studies.

The antigens recognized by these MAbs were identified by SDS-PAGE and western blotting. SDS-PAGE analysis of the crude extract of $P$. halstedii race 100 , performed on a 5 to $15 \%$ polyacrylamide gel under nonreducing conditions, revealed after Coomassie blue staining about 15 major proteins with a molecular mass ranging from 20 to $250 \mathrm{kDa}$ (Fig. 3, lane 1). Among these proteins, only one with an apparent molecular mass of $48 \mathrm{kDa}$ was

TABLE 1. Susceptibility of antigens detected by monoclonal antibodies (MAbs) 16A6 and 2F9 to enzymatic and chemical treatments as determined by enzyme-linked immunosorbent assay

\begin{tabular}{lcc}
\hline \multirow{2}{*}{ Treatment of } & \multicolumn{2}{c}{ Relative bindinga $(\%)$} \\
\cline { 2 - 3 } Plasmopara halstedii extract & MAb 16A6 & MAb 2F9 \\
\hline None & 100 & 100 \\
Phosphate-buffered saline alone & 97 & 96 \\
Proteinase K & 3 & 72 \\
Pronase E & 2 & 85 \\
Acetate buffer alone & 95 & 97 \\
Periodate & 41 & 26
\end{tabular}

a Results, which correspond to the mean of triplicate determinations, are expressed as binding relative to the control performed in the absence of any treatment of the antigens. 
revealed after electrotransfer and immunodetection using MAb 16A6 as probe (Fig. 3, lane 3). The other MAb, MAb 2F9, labeled substances migrating as a "smear" with apparent molecular masses in the range of 20 to $45 \mathrm{kDa}$ (Fig. 3, lane 8). Similar results were obtained when electrophoresis was performed under reducing conditions (data not shown). A control consisting of incubation of the blot with PBS instead of undiluted culture supernatants was negative (Fig. 3, lane 2).

Western blotting and ELISA established the differences in the biochemical nature of the antigens. Treatment of blots of the crude extract with pronase $\mathrm{E}$ or proteinase $\mathrm{K}$ resulted in a complete loss of the immunoreactivity with MAb 16A6 (Fig. 3, lanes 4 and 5),
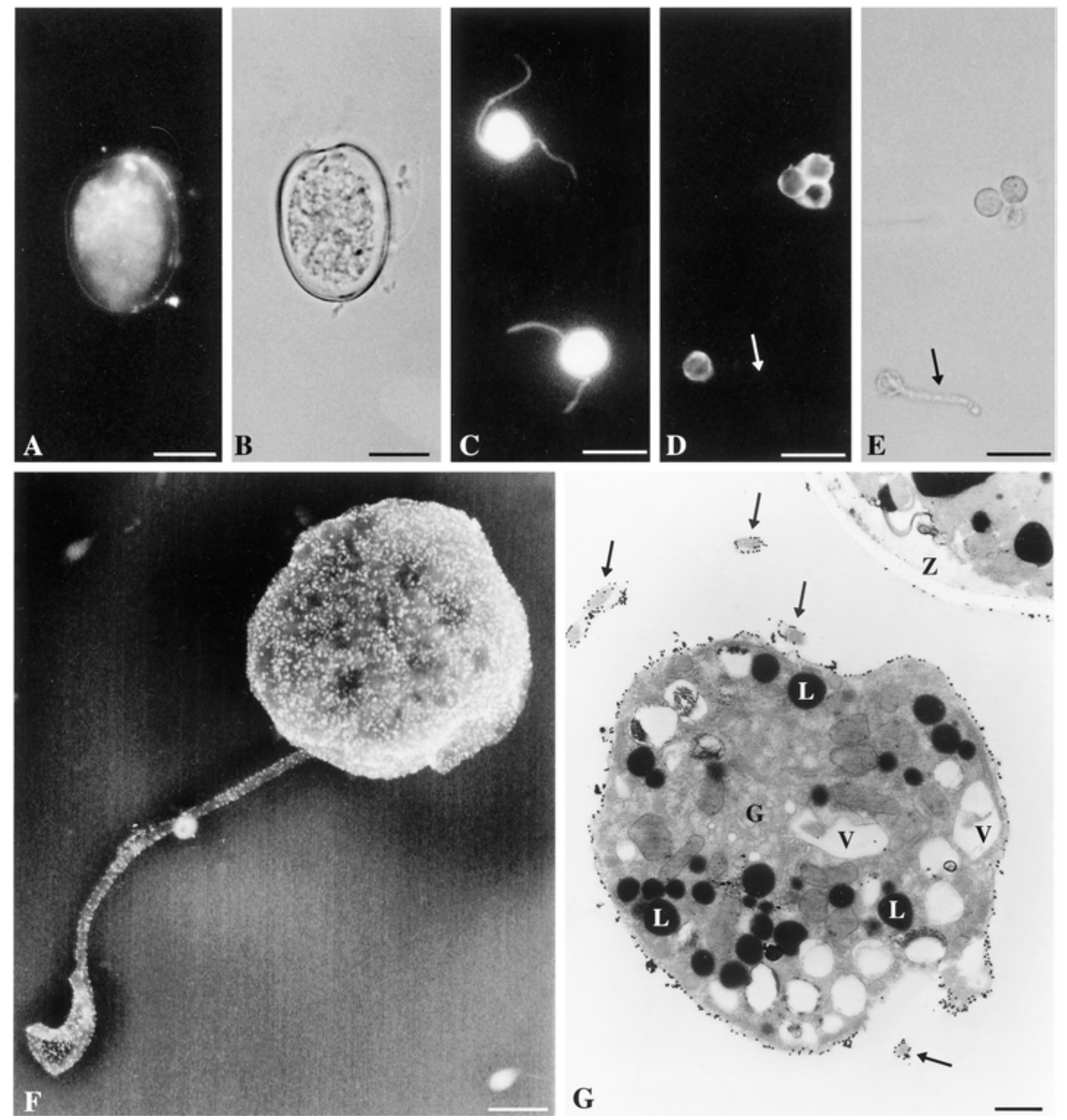

G

Fig. 4. Immunocytochemical labeling of different morphological stages of Plasmopara halstedii with monoclonal antibody 16A6. A, Immunofluorescence microscopy and $\mathbf{B}$, phase-contrast microscopy of nonmature zoosporangia. A, The granular cytoplasmic mass of the zoosporangia brightly fluoresced, whereas $\mathbf{B}$, a faint fluorescence was seen on the cell wall surface visualized on the same field by phase-contrast microscopy. C, Immunofluorescence staining of zoospores. Cell bodies and flagella were uniformly and intensively labeled. D, Immunofluorescence staining of encysted zoospores and germ tubes. Intense staining was detected in the cell wall of encysted zoospores and mother cell of germ tubes, whereas E, no labeling was seen in elongated germ tubes (arrow) visualized by phase-contrast. F, Scanning electron micrograph of a zoospore. Gold particles were homogeneously distributed over the surface of the cell body, as well as along the flagella. G, Transmission electron micrograph of a section of a zoospore. Gold particles appeared closely associated with the plasma membrane of the cell body and with sections of the flagella (arrows). In contrast, note the weak labeling of the cell wall of an adjacent zoosporangium (Z). Golgi apparatus (G), vacuoles (V), and lipid globules (L) were clearly seen in the cytoplasm. Bars correspond to A to E, $10 \mu \mathrm{m}$ or $\mathbf{F}$ and $\mathbf{G}, 1 \mu \mathrm{m}$. 
whereas the immunoreactivity with MAb $2 \mathrm{~F} 9$ was not affected (Fig. 3, lanes 9 and 10). Samples treated with $20 \mathrm{mM}$ periodate showed complete loss of the immunoreactivity with MAb 2F9 (Fig. 3, lane 11) and reduction of the immunoreactivity with MAb 16A6 without modification of molecular mass (Fig. 3, lane 6).
Conversely, immunodetection with the two MAbs was not affected by pretreatment of blots with acetate buffer alone (Fig. 3, lanes 7 and 12) or with PBS. ELISA confirmed the differences in the susceptibility of the respective epitopes, because a complete loss of binding was observed for MAb 16A6 after treatment of the
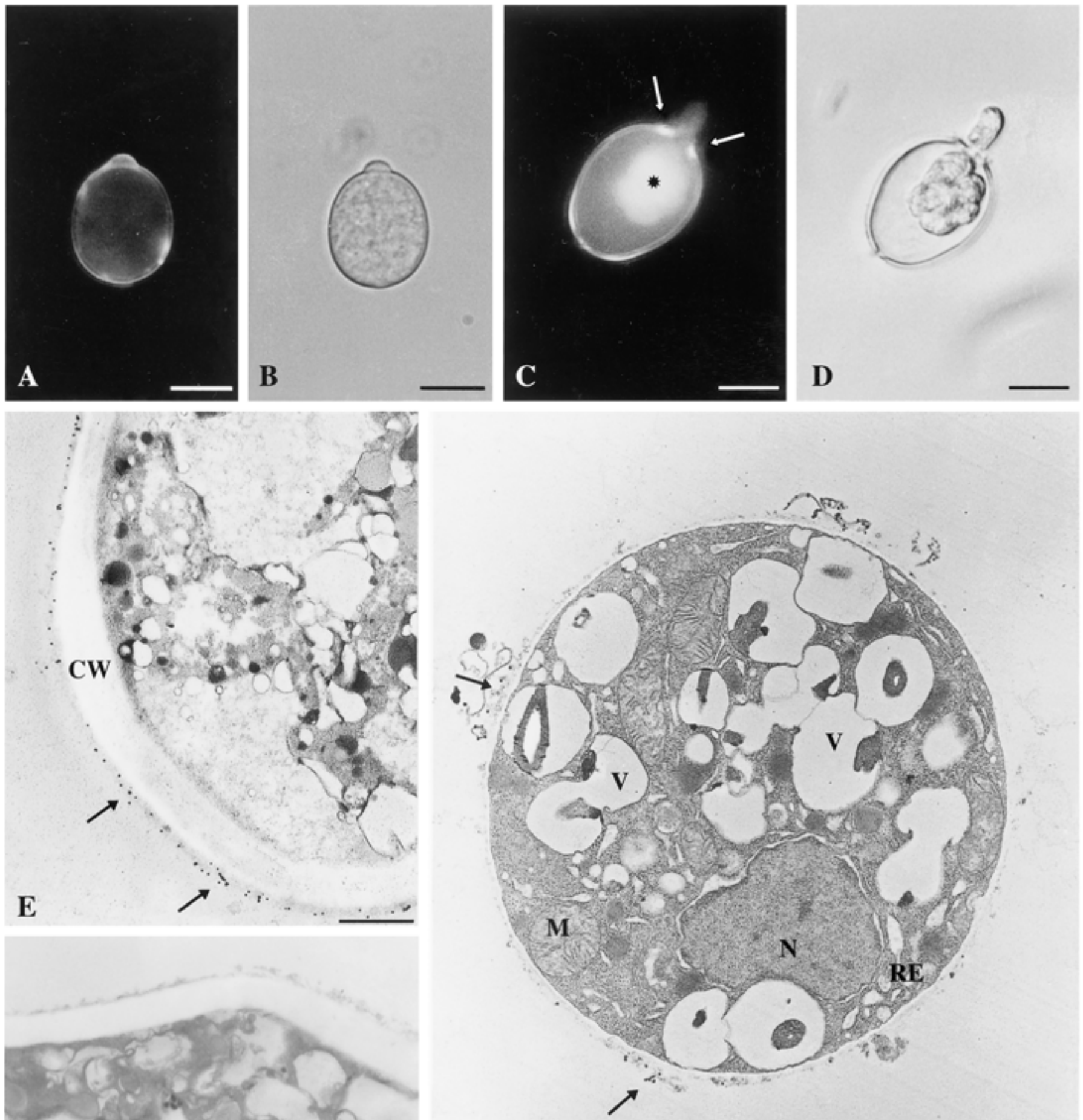

F

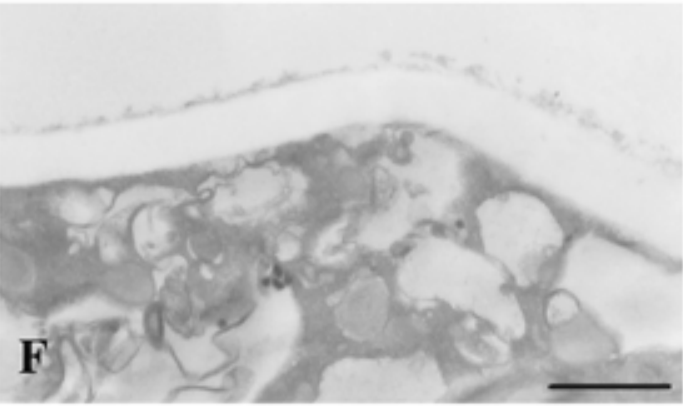

\section{G}

Fig. 5. Immunocytochemical labeling of different morphological stages of Plasmopara halstedii with monoclonal antibody (MAb) 2F9. A to D, Immunofluorescence staining of zoosporangia. A, Immature zoosporangium showing irregular labeling of its cell wall, whereas no staining was detected in the cytoplasm. B, Phase-contrast picture of the same element. C, Mature zoosporangium flushing out its cytoplasmic content. Some well-defined areas of the cell wall, more particularly around the papilla (arrows), fluoresced brightly. Note the diffuse staining of the cytoplasmic content (asterisk). D, Phase-contrast picture of the same element. E and F, Transmission electron micrographs of zoosporangia. E, Gold particles were distributed over the cell wall (CW), associated with the outer electron-dense layer (arrows). F, Control section of zoosporangia treated with an unrelated MAb. The fibrillar network surrounding the cell wall was devoid of any labeling. G, Transmission electron micrograph of an encysted zoospore. Only a few scattered gold particles were seen in some areas of the amorphous electron-dense material surrounding the cell wall (arrows). Mitochondria (M), vacuoles (V), cisternae of granular endoplasmic reticulum (RE), and nucleus $(\mathrm{N})$ were clearly visible on this section. Bars correspond to $\mathbf{A}$ to $\mathbf{D}, 10 \mu \mathrm{m}$ or $\mathbf{E}$ to $\mathbf{G}, 1 \mu \mathrm{m}$. 
coated plates with proteolytic enzymes, whereas no effect was noted for the other MAb (Table 1). Likewise, periodate oxidation of coated plates slightly affected the binding of MAb 16A6, but caused a more pronounced reduction of the binding for the other MAb.

Immunolocalization of the antigens. Antigen expression at the surface of the different morphological stages of $P$. halstedii was examined by immunofluorescence and immunoelectron microscopy. Different binding patterns were observed for the two MAbs. Incubation with MAb 16A6 showed a faint fluorescence in some areas of the surface of zoosporangia, whereas their granular cytoplasmic content fluoresced brightly (Fig. 4A and B). These findings were consistent with the presence of the epitope in mobile zoospores, which exhibited a strong fluorescence on both their plasma membrane and their flagella (Fig. 4C). MAb 16A6 also intensively labeled the cell wall of encysted zoospores and mother cells of germ tubes, whereas the hyphal part of germ tubes was not labeled (Fig. 4D and E).

In scanning immunoelectron microscopy, gold particles appeared distributed uniformly over the surface of mobile zoospores, including their flagella (Fig. 4F). TEM confirmed these results because gold labeling was detected on zoospores, homogeneously distributed as single particles along the plasmalemma, whereas very few particles were seen at the surface of zoosporangia (Fig. 4G).

A different binding pattern was obtained for MAb 2F9. Immunofluorescence revealed for this $\mathrm{MAb}$ an intense labeling of the cell wall surface of zoosporangia (Fig. 5A to D), particularly in defined areas surrounding the papilla. The cytoplasmic content also exhibited a strong fluorescence (Fig. 5C). The labeling of the cell wall of zoosporangia was confirmed by TEM, which showed numerous gold particles associated with the outer electron-dense layer of the wall (Fig. 5E). The surface of flagellate zoospores also fluoresced brightly (data not shown), but little or no reaction was observed with encysted zoospores. Indeed, in some cases, few scattered gold particles were observed over some areas of their cell walls (Fig. 5G). Control sections incubated with a nonspecific $\mathrm{MAb}$ or without the primary antibody were free of any labeling (Fig. 5F).

\section{DISCUSSION}

The asexual phase of the biological cycle of $P$. hasltedii is considered an important factor in the propagation of the disease. However, literature on the morphological and ultrastructural changes that occur during this phase is rather limited. Our observations from phase-contrast and electron microscopy confirmed the tree-like sporangiophores on the leaf surface. As described by Hall (10), sporangiophores were branched at right angles in their upper part with secondary branches also diverging at right angles. The latter divided into two to five sterigmata, each bearing a zoosporangium. After their dispersal, zoosporangia exhibited a basal scar, which could correspond to their insertion point on sterigmata.

Incubation in $1 \%$ saccharose at 16 to $18^{\circ} \mathrm{C}$ enabled the zoosporangia to differentiate, leading to zoospores that were released in the surrounding medium by their flagella through an apical papilla. The two flagella, which allow the mobility of zoospores in a humid environment and their migration toward the host plant tissues, are usually described as the one whiplash and the other tinsel (21). However, SEM demonstrated that both flagella of mobile zoospores of $P$. halstedii were completely smooth. The flagella, which arose laterally from the same area of the cell, then disappeared, leading to encysted zoospores, which presented two puffy rounded scars corresponding to the insertion points of the flagella. Finally, germ tubes detected in our experimental conditions after 3 - $\mathrm{h}$ incubation arose from encysted zoospores.
All these morphological changes were associated with ultrastructural modifications. Thus, the maturation of zoosporangia was characterized by important changes of their cytoplasm, which differentiated into zoospores, as attested by the numerous nuclei and flagellar sections. Changes also occurred during the encystment of zoospores with (i) loss of their flagella; (ii) synthesis of a cell wall responsible for changes in cell shape, which became more regular, globose to subglobose; and (iii) deposition at their surface of an amorphous electron-dense material as already described during the encystment of zoospores in other Oomycetes $(8,12)$. Further investigations are needed to determine if this amorphous material is involved in adherence to the host tissues, as evidenced for encysted zoospores of Phytophthora palmivora (19).

Biochemical changes also occurred during the in vitro development of $P$. halstedii, as attested by the immunostaining procedures. Among the different hybridoma produced in our laboratory, two Mabs, designated 16A6 and 2F9, recognizing different biochemical structures were selected to illustrate these biochemical changes. Indeed, MAb 16A6 specifically recognized a unique $48-\mathrm{kDa}$ glycoprotein, and the complete loss of the immunoreactivity after proteinase treatment of the extract revealed the proteinaceous nature of the epitope. However, considering the partial decrease of the immunoreactivity after periodate treatment, an alternative interpretation of the data would be a conformational epitope involving both protein and carbohydrate moieties of this glycoprotein. In contrast, MAb 2F9 bound to components with apparent molecular masses ranging from 20 to $45 \mathrm{kDa}$, and periodate treatment of the extract led to the complete loss of the immunoreactivity. These results suggested highly glycosylated antigens and a carbohydrate epitope.

Immunofluorescence and electron microscopy showed that the antigen recognized by MAb 16A6 was concentrated mainly on flagellate zoospores, homogeneously distributed over their entire surface, including the flagella, and closely associated with the plasma membrane. Labeling was also detected in the cell wall of encysted zoospores, thus providing evidence for the passage of the molecule through the periplasmic space and for its accumulation in the newly synthesized cell wall. However, no labeling was observed on the hyphal wall of germ tubes, indicating a close association between surface expression of the 48-kDa antigen and the zoospores of $P$. halstedii. In contrast, MAb 2F9 intensively labeled well-defined areas of the cell wall of zoosporangia. The epitopes were localized on the outer cell wall layer, associated with a fibrillar network resembling that extensively described in some pathogenic fungi $(1,23)$. The surface of flagellate zoospores also brightly fluoresced after incubation with MAb 2F9. However, the epitopes were not detected at the surface of encysted zoospores, suggesting their loss during the encystment or their masking by an amorphous electron-dense material deposited around the cell. These findings are consistent with previous reports on some Phytophthora or Blastocladiella species showing a marked decrease in the density of carbohydrate residues at the surface of zoospores during their encystment $(11,13)$.

Together these results provide new insights into the morphological and ultrastructural changes that occur during the asexual phase of the life cycle of $P$. halstedii. Most previous ultrastructural studies have focused on its penetration into cells of susceptible hosts $(9,24)$. However, earlier events like the release of flagellate zoospores, their migration toward the host, and their encystment may also be interesting targets for the development of new antimicrobial products against this pathogen. In this context, our MAbs were effective for following the distribution of specific antigens during the asexual development of $P$. halstedii and therefore to investigate the differentiation process from zoosporangia to encysted zoospores and hyphae. In addition, MAbs also promise to be of great value to study the interactions of these antigens with host cells. 


\section{ACKNOWLEDGMENTS}

This work was supported by a grant from Contrat de Plan Etat-Région Pays de la Loire 1994 to 1998 "III-Appréciation et contrôle de la qualité sanitaire des semences." We thank S. Aligon and C. Giroult from GEVES (Angers, France) for production of infected seedlings, and D. McIlroy (INSERM U 419, Nantes, France) for proofreading the manuscript.

\section{LITERATURE CITED}

1. Benhamou, N., and Ouellette, G. B. 1986. Use of pectinases complexed to colloidal gold for the ultrastructural localization of polygalacturonic acids in the cell walls of the fungus Ascocalyx abietina. Histochem. J. 18:95-104.

2. Benz, A., and Spring, O. 1995. Identification and characterization of an auxin-degrading enzyme in downy mildew infected sunflower. Physiol. Mol. Plant Pathol. 46:163-175.

3. Bouterige, S., Robert, R., Bouchara, J. P., Marot-Leblond, A., Molinéro, V., and Senet, J. M. 2000. Production and characterization of two monoclonal antibodies specific for Plasmopara halstedii. Appl. Environ. Microbiol. 66:3277-3282.

4. Cachinero, J. M., Cabello, F., Jorrin, J., and Tena, M. 1996. Induction of different chitinase and $\beta$-1,3-glucanase isoenzymes in sunflower (Helianthus annuus L.) seedlings in response to infection by Plasmopara halstedii. Eur. J. Plant Pathol. 102:401-405.

5. Champion, R. 1983. Essais de résistance des cultivars aux maladies en France. Seed Sci. Technol. 11:681-690.

6. Cohen, Y., and Sackston, W. E. 1973. Factors affecting infection of sunflower by Plasmopara halstedii. Can. J. Bot. 51:15-22.

7. Delanoé, D. 1972. Biologie et épidémiologie du mildiou du tournesol (Plasmopara helianthi Novot.). Inform. Techniq. CETIOM 29:1-49.

8. Desjardins, P. R., Wang, M. C., and Bartnicki-Garcia, S. 1973. Electron microscopy of zoospores and cysts of Phytophthora palmivora: Morphology and surface texture. Arch. Mikrobiol. 88:61-70.

9. Gray, A. B., Sackston, W. E., and Thauvette, L. 1985. The development of infection structures of Plasmopara halstedii in suspensions of sunflower cells. Can. J. Bot. 63:1817-1819.

10. Hall, G. 1989. Plasmopara halstedii. CMI descriptions of pathogenic fungi and bacteria, No. 979. Mycopathologia 106:205-207.

11. Hardham, A. R., and Suzaki, E. 1990. Glycoconjugates on the surface of spores on the pathogenic fungus Phytophthora cinnamomi studied using fluorescence and electron microscopy and flow cytometry. Can. J. Microbiol. 36:183-192.

12. Heath, I. B., and Greenwood, A. D. 1970. Wall formation in the Saprolegniales. Arch. Mikrobiol. 75:67-79.

13. Jen, C. J., and Haug, A. 1979. Changes in surface properties of developing zoospores of Blastocladiella emersonii: Binding of concanavalin A. J. Gen. Microbiol. 115:145-151.

14. Laemmli, U. K. 1970. Cleavage of structural proteins during the assembly of the head of bacteriophage T4. Nature (London) 227:680-685.

15. Lafon, S., Penaud, A., Walser, P., De Guenin, M. C., Molinéro, V., Mestre, R., and Tourvieille de Labrouhe, D. 1996. Le mildiou du tournesol toujours sous surveillance. Phytoma-La Défense des Végétaux 484:35-37.

16. Marot-Leblond, A., Robert, R., Aubry, J., Ezcurra, P., and Senet, J. M. 1993. Identification and immunochemical characterization of a germ tube specific antigen of Candida albicans. FEMS Immunol. Med. Microbiol. 7:175-186.

17. Oros, G., and Viranyi, F. 1986. Tridemorph acts on the cell membrane of Plasmopara halstedii. Acta Phytopathol. Entomol. Hungarica 21:157164.

18. Sackston, W. E. 1981. Downy mildew of sunflower. Pages 545-575 in: The Downy Mildews. D. M. Spencer, ed. Academic Press, London.

19. Singh, V. O., and Bartnicki-Garcia, S. 1975. Adhesion of Phytophthora palmivora zoospores: Electron microscopy of cell attachment and cyst wall fibril formation. J. Cell Sci. 18:123-132.

20. Spring, O., Benz, A., and Faust, V. 1991. Impact of downy mildew (Plasmopara halstedii) infection on the development and metabolism of sunflower. J. Plant Dis. Prot. 98:597-604.

21. Tourvieille de Labrouhe, D., Pilorgé, E., Nicolas, P., and Vear, F. 2000. Le mildiou du tournesol. Points Techniques. CETIOM, INRA.

22. Towbin, H., Staehelin, T., and Gordon, J. 1979. Electrophoretic transfer of proteins from polyacrylamide gels to nitrocellulose sheets: Procedure and application. Proc. Natl. Acad. Sci. USA 76:4350-4354.

23. Tronchin, G., Poulain, D., Herbaut, J., and Biguet, J. 1981. Cytochemical and ultrastructural studies of Candida albicans. II. Evidence for a cell wall coat using concanavalin A. J. Ultrastruct. Res. 75:50-59.

24. Wehtje, G., Littlefield, L. J., and Zimmer, D. E. 1979. Ultrastructure of compatible and incompatible reactions of sunflower to Plasmopara halstedii. Can. J. Bot. 57: 315-323.

25. Woodward, M. R., Young, W. W., Jr., and Bloodgood, R. A. 1985. Detection of monoclonal antibodies specific for carbohydrate epitopes using periodate oxidation. J. Immunol. Methods 78:143-153. 